\title{
Molecular Circuits of Resolution in Renal Disease
}

\author{
Emma Börgeson and Catherine Godson* \\ UCD Diabetes Research Centre, UCD Conway Institute, School of Medicine and \\ Medical Sciences, University College Dublin \\ E-mail: catherine.godson@ucd.ie
}

Received March 19, 2010; Revised May 18, 2010; Accepted May 20, 2010; Published July 7, 2010

Inflammation is a common feature of renal pathology. Lipid mediators, such as lipoxins, resolvins, and protectins, can actively promote the resolution of inflammation by inhibiting polymorphonuclear cell infiltration to the site of inflammation, shifting the cytokine milieu from proinflammatory to proresolving and increasing the nonphlogistic phagocytosis of apoptotic cells by macrophages. Here we review the evidence for molecular circuits of resolution in renal disease.

KEYWORDS: lipxoins, resolvins, protectins, renal inflammation

\section{RESOLUTION OF INFLAMMATION}

Effective host defense requires an initial inflammatory response that dissipates to ensure tissue homeostasis[1,2]. Conventionally, the dissipation of inflammatory responses was presumed to reflect a decline in proinflammatory mediators. However, over the past decade, there has been a paradigm shift in our understanding of these processes and it is now appreciated that the resolution of inflammation is an actively managed process. A major contribution to our understanding of the resolution of inflammation has been made by investigations of lipid mediator biosynthesis during inflammation[2]. These studies have identified distinct, proresolving bioactions of lipoxins (LXs) and, more recently, resolvins and protectins[3]. Failure of resolution can result in abscess formation, scarring, fibrosis, and eventual organ failure, and subversion of resolution may be reflected in many prevalent chronic diseases, such as arthritis, diabetes, and atherosclerosis[1,2].

An inflammatory insult causes localized production of lipid mediators, such as prostaglandins (PGs) and leukotrienes (LTs), whose proinflammatory bioactions are crucial for host defense. PGs cause vasodilatation, which facilitates the recruitment of leukocytes and monocytes, and LTs are potent chemoattractants that guide the newly recruited polymorphonuclear cells (PMNs) to the site of injury via diapedesis. In this manner, a functional acute inflammatory response arises. Interestingly, it has been shown that the same mechanisms that induce inflammation also program its resolution[4]. The signaling pathways inducing PGE2 and PGD2 formation actively switch the production of lipid mediators from proinflammatory to proresolving by inducing 15-lipoxygenase (LO), which is required for production of LXs, protectins, and resolvins[5]. These proresolving mediators reduce vascular permeability, inhibit PMN recruitment, promote infiltration of monocytes, and stimulate the nonphlogistic phagocytosis of apoptotic 
PMNs by macrophages $(\mathrm{M} \phi)$, which is a crucial process in resolution[2] (Fig. 1). It has furthermore been proposed that these proresolving mediators might also stimulate the lymphatic drainage of leukocytes[4].

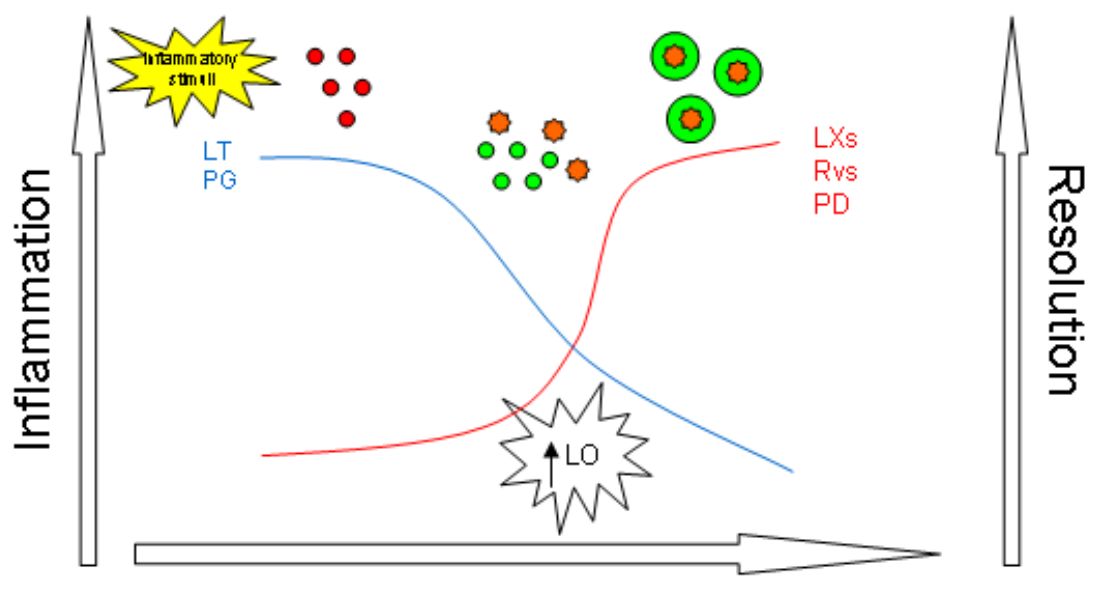

$\begin{aligned}-= & \text { PMN } \\ = & \text { apoptotic PMN } \\ = & \text { Monocytes } \\ = & \text { M } \phi \text { non-phlogistically } \\ & \text { phagocytosing apoptotic PMN }\end{aligned}$

\section{Time}

FIGURE 1. Temporal lipid inflammation and its resolution. Leukotrienes (LT) and prostaglandins (PG) are synthesized in response to an inflammatory stimulus. These induce vasodilatation and facilitate the recruitment of polymorphonuclear cells (PMNs) into the tissue, which attempt to rid the tissue of the inflammatory stimuli and clear tissue debris. As the inflammation progresses, PGs induce transcription of 15lipoxygenase (LO) in neutrophils, which induces the formation of lipoxins (LXs), and potentially also resolvins and protectins[5]. These mediators promote the resolution of inflammation by inhibiting PMN infiltration, while stimulating the recruitment of monocytes, inducing a shift in the cytokine milieu and stimulating macrophage $(\mathrm{M} \phi)$ phagocytosis of apoptotic PMN in a nonphlogistic manner[1,2].

Inflammation is a feature of most renal pathology, and severe acute or chronic renal inflammation may lead to glomerulosclerosis, tubular atrophy, damage to renal vasculature, and fibrosis[6]. The pathogenesis of renal inflammation is complex, but irrespective of the initial stimulus, infiltration of neutrophils and monocytes are cardinal signs[6]. Some kidney diseases, such as poststreptoccocal glomerulonephritis, resolve on their own, demonstrating the endogenous ability of repair[7]. In other types of renal disease, such as diabetic nephropathy, the inflammation becomes chronic and causes significant organ injury[8]. Resolution of renal inflammation involves removal of apoptotic cells, leukocytes, and a change of the cytokine milieu from proinflammatory to anti-inflammatory and proresolving[6]. However, the mechanisms by which this occurs and may be subverted in disease are only beginning to be understood. This review aims to clarify some of the mechanisms underlying resolution of renal inflammation, focusing on proresolving lipid mediators such as LXs, resolvins, and protectins.

\section{LIPOXINS}

LXs are endogenously produced eicosanoids with potent anti-inflammatory and proresolving effects. They were discovered in 1984 by Serhan et al. when examining mixed fractions of human leukocytes[9] and were named "lipoxins" since they are lipoxygenase interaction products[10]. Lipoxin $\mathrm{A}_{4}\left(\mathrm{LXA}_{4}\right)$ and its positional isomer lipoxin $\mathrm{B}_{4}\left(\mathrm{LXB}_{4}\right)$ are the principal species found in mammals. 


\section{Biosynthesis}

LXs are generated from the $\omega-6$ fatty acid, arachidonic acid (AA), in a transcellular manner by the sequential action of 5-LO and either 12-LO or 15-LO[11,12] (Fig. 2). They are produced at local sites of inflammation between neutrophils, platelets, and resident tissue cells, such as epithelial cells, where they are active within the pico- to nanomolar range[13,14]. An interesting aspect of LX biosynthesis was discovered in 1990 by Brezinski and Serhan[15] as they learned that leukocytes can be primed for LX synthesis. Their work shows that 15-hydroxyeicosatetraenoic acid (HETE) can be stored in the membrane of neutrophils. Upon activation of the cell, 15-HETE is released and taken up by neighboring leukocytes, which in turn transform it into $\mathrm{LXA}_{4}$ or $\mathrm{LXB}_{4}[15]$, indicating that leukocytes may be primed for resolving actions. LX formation can also be induced by aspirin, which, under cytokine-primed conditions, can acetylate cyclooxygenase-2 (COX-2) and thus shift its activity from that of an endoperoxidase to a lipoxygenase[16]. Aspirin inhibits both COX-1 and COX-2 by acetylating a serine residue near the active site, inducing conformational changes that inhibit the oxidation of $\mathrm{AA}$ to $\mathrm{PGH}_{2}$, which is the precursor of PGs and thromboxanes. However, although COX-1 is completely inhibited, COX-2 acetylated by aspirin retains catalytic activity to produce 15-HETE from AA, which may in turn be transformed into 15-epi-

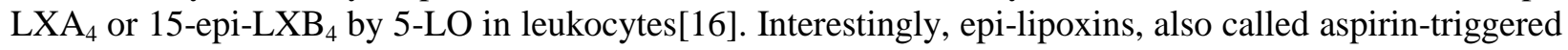
lipoxins (ATLs), are even more potent than their precursors and could potentially be responsible for the beneficial effect of aspirin, e.g., in cardiovascular disease[17,18]. Aspirin-stimulated generation of ATLs and inhibition of thromboxane production has been shown to be dose dependent, with low-dose aspirin being most effective[19]. Interestingly, it has been proposed that combined low-dose aspirin, statins, and thiazolidinediones are effective mediators of vessel wall inflammation, whereas high-dose aspirin in combination with these agents has potential adverse effects[20].

\section{Metabolic Inactivation of Lipoxins}

Native LXs undergo rapid inactivation in vivo, primarily by PG dehydrogenase-mediated oxidation and reduction[21]. Thus, efforts have been made to design chemically stable LX analogues. The first LX analogues were created in 1995 by Serhan et al.[21] and since then, numerous attempts have been made to design analogues that, while withstanding degradation and inactivation, retain the potent biological activity of native LXs[22,23,24]. Each action of LXs is highly stereoselective[25], and there are three main features that influence the stability and potency of the compound. First, the $R$ rather then the $S$ configuration at C-15 enhances the activity. This is demonstrated by the fact that the native $\mathrm{LXA}_{4}$ has an $S$ configuration, while ATL has an $R$ configuration at C-15[26], and the latter molecule is reportedly more potent; for instance, in experimental assays investigating neutrophil migration[27]. It has also been shown that a $5 S-6 R$-orientation at the two hydroxyl groups, as well as a cis-conformation at $\mathrm{C}-11$, enhances the activity of LXs. One of the first LX-generated analogues made was the 15-epi-16-( $p$-fluoro)-phenoxy$\mathrm{LXA}_{4}$, which was proven to have many beneficial proresolving effects; for instance, in ischemic acute renal failure[28]. A second generation of LX/ATL analogues was designed where the intent was to avoid metabolism by $\beta$-oxidization through insertion of a 3-oxa group. These have a similar biologic activity as the 15-epi analogues, but with a better pharmacokinetic profile[1,29]. More recently, a new type of analogue has been designed featuring a benzo-fused ring system. These have been proven to be as potent as native $\mathrm{LXA}_{4}$ both in vivo and in vitro, and thus hold potential as therapeutics[30,31].

\section{Lipoxin Bioactions}

LXs have well-established, anti-inflammatory, proresolving, and antifibrotic bioactions, as reviewed in $[1,2,32]$, and have proven to be protective in many models of inflammatory diseases, such as inflammatory bowel diseases[23], periodontal disease[33,34,35], and cardiovascular disease[11]. LXs 

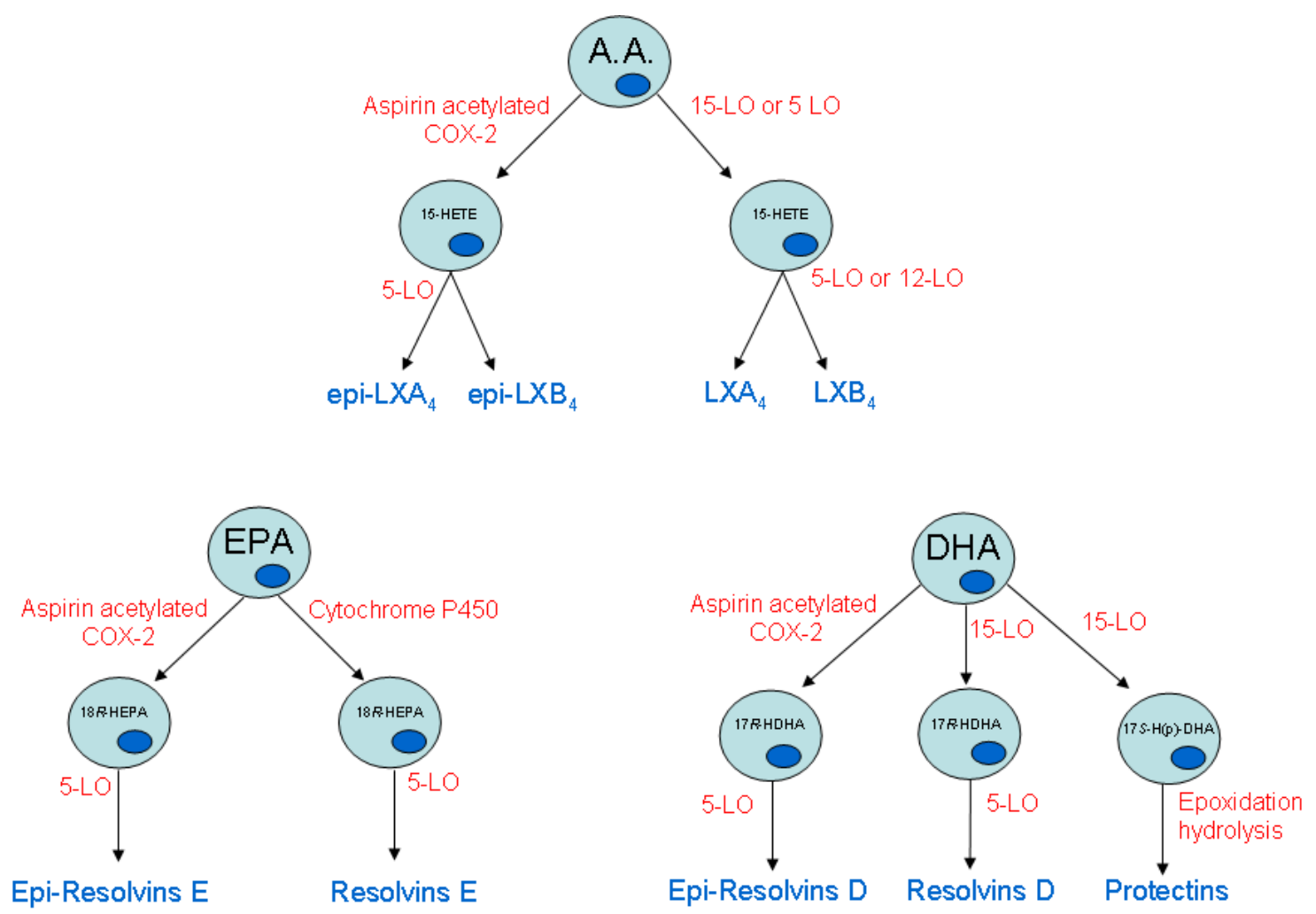

FIGURE 2. Biosynthesis of lipoxins, resolvins, and protectins. Lipoxins (LXs) are generated from arachidonic acid (AA) in a transcellular manner involving neutrophils, platelets, and resident tissue cells, such as epithelial cells. AA is transformed by the sequential action of lipoxygenase (LO) into $\mathrm{LXA}_{4}$ or $\mathrm{LXB}_{4}$ with 15-hydroxyeicosatetraneoic acid (HETE) as the intermediate product $[11,12]$. LX formation can also be induced by aspirin, which acetylates cyclooxygenase-2 (COX-2) and thus shifts its activity from that of an endoperoxidase to a lipoxygenase and enables it to produce 15-HETE from AA, which may in turn be transformed into 15-epi-LXA ${ }_{4}$ or 15-epi-LXB 4 by 5-LO in leukocytes[16]. Resolvins are generated from eicosapentaenoic acid (EPA) or docosahexaenoic acid (DHA). EPA can be enzymatically converted by cytochrome P450 or acetylated COX-2 into $18 R$ HEPA, which can be further transformed by enzymatic epoxidation and 5-LO in leukocytes to form E series resolvins (RvE)[52]. DHA can be converted in a similar manner by the sequential activation of $15-\mathrm{LO}$ or acetylated COX-2 into 17R-HDHA, which is then transformed by enzymatic epoxidation and 5-LO to form D series resolvins (RvD)[52]. Protectins are similarly generated from DHA, but via a separate pathway involving 15-LO and enzymatic epoxidation and hydrolysis, where $17 S-\mathrm{H}(\mathrm{p})$-DHA serves as the intermediate product[3].

limit leukocyte chemotaxis[36] and inhibit activation of neutrophils and eosinophils[37]. They also stimulate expression of genes involved in resolution[38] and regulate NF- $\kappa \mathrm{B}$ activation[39]. Furthermore, they stimulate nonphlogistic $\mathrm{M} \phi$ phagocytosis of apoptotic PMN both in vitro and in vivo[32,40], which is also associated with a shift from release of proinflammatory to anti-inflammatory cytokines[41]. LXs can also act as vasodilators[42] and can reprogram $\mathrm{M} \phi$ from a classically activated (M1) phenotype to an alternative phenotype[40]. The primary $\mathrm{LXA}_{4}$ receptor first identified in neutrophils by Fiore et al.[43] was a G protein-coupled receptor (GPCR) designated as FPR2/ALX[43,44], which is a receptor that binds pleiotropic ligands, both lipids and small peptides, and elicits either proinflammatory or antiinflammatory responses[1]. Krishnamoorthy et al. recently found that $\mathrm{LXA}_{4}$ can interact with another GPCR, namely GPR32[45]. It is noteworthy that although $\mathrm{LXA}_{4}$ and $\mathrm{LXB}_{4}$ share biological activities and structures, $\mathrm{LXB}_{4}$ does not bind FPR2/ALX and the $\mathrm{LXB}_{4}$ receptor has not yet been identified. $\mathrm{LXA}_{4}$ has also displayed partial antagonism of a subclass of peptide-LT receptors (CysLTs)[1]. Cross-talk between FPR2/ALX and growth factor receptors also poses a mechanism by which LXA $_{4}$ indirectly inhibits cellular responses, such as mesangial proliferation, angiogenesis, and fibrosis[1,46,47]. Finally, $\mathrm{LXA}_{4}$ has been suggested to bind the nuclear aryl hydrocarbon receptor (AhR) in dendritic cells, although far greater 
concentrations of $\mathrm{LXA}_{4}$ are needed for activation of this receptor compared to the GPCR[48]. It is noteworthy that, as many of the bioactions of LXs ascribe an anti-inflammatory and proresolving phenotype, they conversely down-regulate immune responses to pathogens such as Mycobacterium tuberculosis and Toxoplasma gondii[49,50,51]. These findings emphasize the importance of the temporal and spatial regulations of eicosanoid production in effective host defense.

\section{RESOLVINS AND PROTECTINS}

\section{Biosynthesis}

Resolvins, "resolution phase interaction products", and protectins are generated from the $\omega-3$ polyunsaturated fatty acids (PUFAs) eicosapentaenoic acid (EPA) or docosahexaenoic acid (DHA) (Fig. 2 ). EPA can, by a series of enzymatic reactions involving cytochrome P450, be converted to $18 R$-HEPA, which can be further transformed by enzymatic epoxidation and 5-LO in leukocytes to form E series resolvins (RvE). DHA can be converted in a similar manner into $\mathrm{D}$ series resolvins (RvD) by the sequential activation of 15-LO, enzymatic epoxidation, and 5-LO, where 17R-HDHA is the intermediate product[52]. Similarly to resolvins, protectins are generated from DHA, but via a pathway involving 15LO and enzymatic epoxidation and hydrolysis where $17 S-\mathrm{H}(\mathrm{p})$-DHA serves as the intermediate product[3]. As with the ATLs, there are aspirin-triggered epimers of the resolvins where the formation is induced by acetylated COX-2[2].

\section{Bioactions}

Both resolvins and protectins display potent anti-inflammatory and proresolving effects by inhibiting production of anti-inflammatory mediators, regulating neutrophil trafficking, and promoting nonphlogistic $\mathrm{M} \phi$ phagocytosis of apoptotic cells[3,53]. RvE1 was protective in peridontitis, reducing PMN infiltration, preventing bone loss, and promoting tissue healing[54]. They have also been shown to limit neutrophil influx in a murine model of colitis[55], as well as being protective against neovascularization in retinopathy[56]. RvD1 limits PMN infiltration in peritonitis and is protective of experimental ischemia/reperfusion (I/R)-induced kidney injury[57]. Protectin D1 (PD1) has, similar to the other $\omega$-3-derived compounds, proven to be beneficial in peritonitis and kidney I/R injury[57], and also in asthma[29] and ischemic stroke[58]. Furthermore, diminished PD1 has been implicated in neural cell survival in Alzheimer's disease[59]. In neutrophils, RvE1 has been shown to bind BLT1, whereas in $\mathrm{M} \phi$ and dendritic cells, it binds ChemR23[60]. RvD1 has also been reported to interact both with FPR2/ALX and GPR32 in phagocytes[45]. It is, however, as of yet, not entirely clear which receptor the protectins act through.

\section{THE KIDNEY}

The kidneys are unique in receiving high blood flow, approximately $25 \%$ of the cardiac output. When the kidneys encounter an insult, adhesion molecules are up-regulated and leukocytes infiltrate the organ and cause inflammation and injury. If kidney injury is not resolved and the inflammation persists, chronic kidney disease (CKD) and end-stage renal failure can develop, with dialysis and transplantation as the only option[61]. In recent years, there has been a massive increase in CKD due to an increase in obesity, hypertension, and diabetes mellitus. Indeed, diabetic nephropathy develops in about $25-40 \%$ of diabetic patients and is the major cause of end-stage kidney failure[62]. CKD is characterized by a progressive loss of real function and accumulation of profibrotic extracellular matrix (ECM), which causes glomerulosclerosis and tubulointerstitial fibrosis[63]. Even though CKD is most often diagnosed well 
before it reaches end-stage kidney failure, there is no treatment as of yet that can halt or reverse the decline in renal function. Since inflammation is a common feature of kidney disease, regardless of initial insult, it may well be worth targeting in drug development, possibly focusing on proresolving mediator such as LXs, resolvins, and protectins.

\section{LIPOXINS, RESOLVINS, AND PROTECTINS IN RENAL DISEASE}

LXs have proven to be proresolving in many types of renal injury, as reviewed in Kieran et al.[64]. LXs play a role in glomerulonephritis, where it reduces proteinuria, glomerular inflammation, and mesangial cell proliferation[65]. Interestingly, both $\mathrm{LXA}_{4}$ and 15-LO are elevated in children with acute poststreptococcal glomerulonephritis throughout the disease process, whereas $\mathrm{LTB}_{4}$ levels peaked during the acute phase and decreased during resolution. Furthermore, $\mathrm{LXA}_{4}$ inhibited $\mathrm{LTB}_{4}$ secretion and also $\mathrm{LTB}_{4}$-induced chemotaxis of PMN isolated from the glomeruli of these children[7]. Leonard et al. have also shown that LXs are also protective in models of acute renal failure (ARF) using a murine I/R model, where an analogue of ATLs gave functional and morphological protection and attenuated chemokine and cytokine responses[28]. Similarly, resolvins and protectins have proven to be important in the resolution of renal disease, attenuating neutrophil influx and $M \phi$ activation[57,66]. Even though clinical trials are not conclusive, it appears through meta-analysis that treatment with fish oil, which is high in $\omega-3$ PUFAs, reduces the risk of end-stage renal disease in dogs[67] as well as in humans [68,69], and DHA specifically has been shown to be renoprotective in mice[70,71]. Furthermore, An et al. showed, using a rat model of $5 / 6$ nephrectomy, which is a model resembling chronic renal failure, that $\omega-3$ PUFAs reduced upregulation of proinflammatory and profibrotic pathways and attenuated tubulointerstitial fibrosis[72]. Duffield et al.[57] first showed, using a renal I/R model in BALB/c mice, that endogenous levels of RvDs and PD1 are increased $24 \mathrm{~h}$ after I/R injury, both in the kidney and in plasma. Hassan and Gronert[66] confirmed these findings by reporting that dietary $\omega-3$ PUFAs increase endogenous renal expression of PD1 and 17-HDHA, the latter being a metabolic marker for RvDs. Furthermore, when given RvDs and PD1 systemically before I/R, the compounds attenuated ischemic kidney injury in a dose-dependent manner[57]. Interestingly, RvDs were also effective when administered after $\mathrm{I} / \mathrm{R}$ for $72 \mathrm{~h}$, reducing fibrosis at day 15 postinjury[57]. This may suggest that they do not only block proinflammatory events, but also contribute actively to resolution (see Fig. 3).

\section{Neutrophil Influx}

LXs inhibit PMN chemotaxis, adhesion, and migration in numerous pathological conditions, ranging from peridontitis to dermal inflammation, and work as a braking signal for PMN-mediated tissue injury[1]. This has also been demonstrated in the kidney, where LXs repeatedly have been proven to reduce PMN influx and thereby preserve renal function and morphology[28]. Since cellular communication is vital in LX biosynthesis, P-selectin-mediated endothelial-PMN interaction facilitates 15-LO-initiated $\mathrm{LXA}_{4}$ biosynthesis[73]. Interestingly, P-selectin-deficient mice, who have reduced $\mathrm{LXA}_{4}$ biosynthesis by $60 \%$, are more susceptible to glomerulonephritis with a marked increase in PMN infiltration. Furthermore, when attempting to restore $\mathrm{LXA}_{4}$ levels by injecting wild-type platelets, PMN infiltration was reduced and glomerulonephritis less severe[74]. Treating rat PMN with $\mathrm{LXA}_{4}$ ex vivo reduces PMN influx to glomeruli in a model of glumerolonephritis[75]. Furthermore, overexpressing 15-LO in rats is protective in experimental glomerulonephritis, reducing inflammation and preserving function, which could be coupled to an increased LX synthesis[76]. Resolvins and protectins also inhibited influx of neutrophils[57], and systemic delivery of PD1 and ATLs reduced PMN recruitment in a mouse model of I/R injury[66]. 


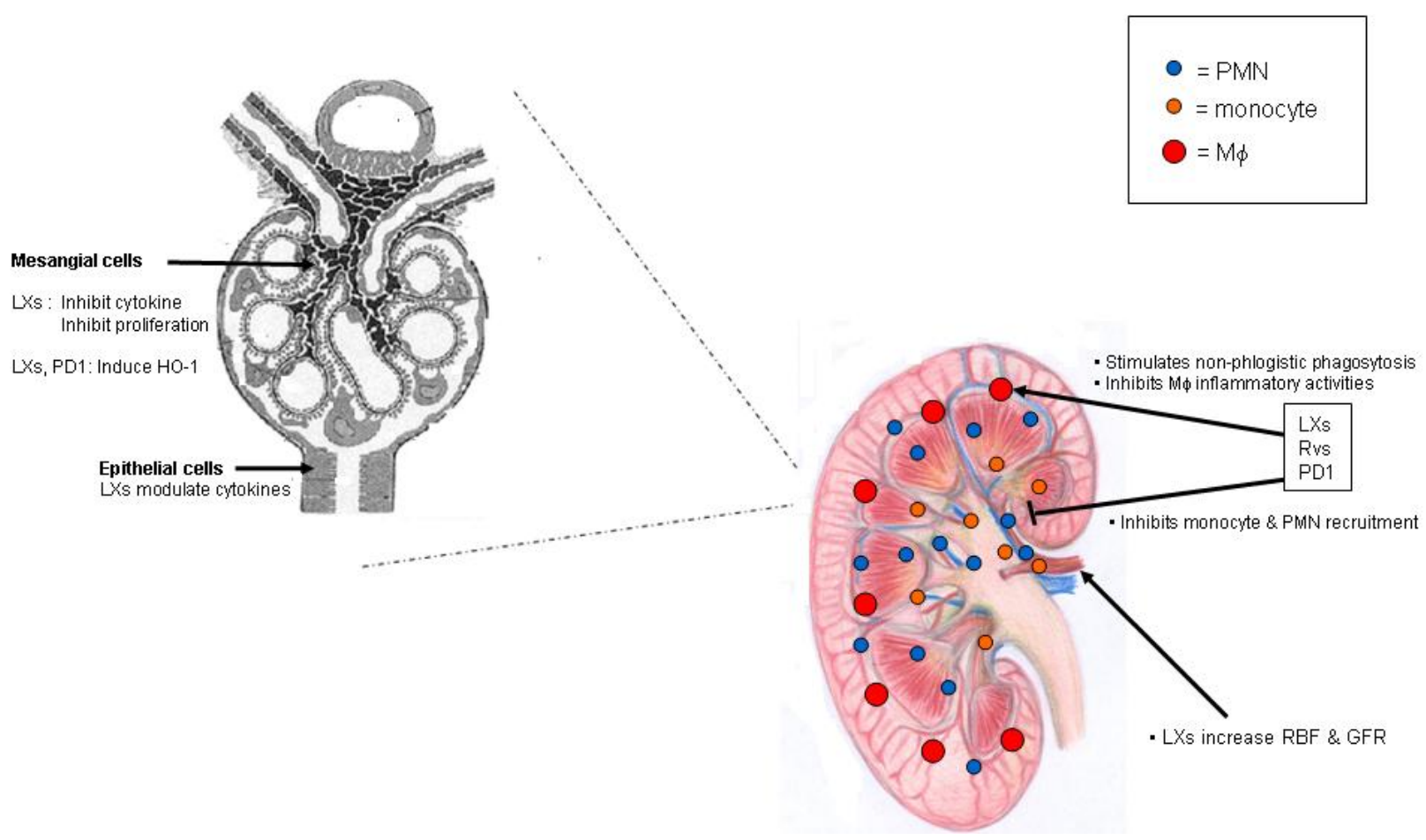

FIGURE 3. Bioactions of lipoxins, resolvins, and protectins during resolution of renal inflammation. As renal inflammation proceeds, leukocyte infiltration is pronounced and causes many deleterious effects. Lipoxins (LXs), resolvins (Rvs), and protectins (PD) inhibit the recruitment of polymorphonuclear cells (PMNs) and monocytes[57]. They also stimulate macrophages $(\mathrm{M} \phi)$ to nonphlogistically phagocytose apoptotic cells and inhibit inflammatory activities of M $\phi$, e.g., by shifting their cytokine production from inflammatory to resolving[64]. LXs have also been shown to increase renal blood flow (RBF) and glomerular filtration rate (GFR)[107]. Furthermore, LXs modulate cytokine production from both epithelial and mesangial cells, as well as inhibit mesangial proliferation[64]. Finally LXs and PD1 induce the hemeoxygenase-1 (HO-1) pathway, which has been shown to be renoprotective[66]. (Modified from Poussu[133].)

\section{Macrophages}

Most renal diseases are characterized by $\mathrm{M} \phi$ infiltration, which promotes inflammation by secreting mediators such as TNF- $\alpha$ and INF- $\gamma$ and contribute to the pathogenesis of fibrosis. However, it is becoming increasingly clear that $\mathrm{M} \phi$ also contribute to the resolution of renal inflammation by traits such as clearing apoptotic cells and production of anti-inflammatory mediators such as IL-10[77]. When $\mathrm{M} \phi$ are recruited to a site of inflammation, they develop phenotypically distinctive features in response to local stimuli. Initial descriptions categorize these as either a "classically activated" and inflammatory M1 phenotype, or an "alternatively activated" phenotype[78]. However, recent data suggest that this might be slightly oversimplifying as there are numerous subtypes of the M2 class, and it has been suggested that perhaps $\mathrm{M} \phi$ phenotypes should be grouped into host defense, wound healing, and immune regulating groups instead[79]. Interestingly, $\mathrm{M} \phi$ are not completely committed to their phenotype, but may change or regress to a resting state depending on their microenvironment. For instance an M1 M $\phi$ can change to a M2 phenotype subsequent to phagocytosis of apoptotic cells[80]. The M2 phenotype has repeatedly been shown to promote resolution[80]. Wang et al. demonstrated the importance of the M $\phi$ phenotype using a murine model of adriamycin nephropathy, manipulating $\mathrm{M} \phi$ ex vivo into either an M1 or M2 phenotype, by stimulating them with either LPS or IL-4/IL-13, respectively. When reinjecting the M $\phi$ into the mice, they could show that an M1 phenotype induced renal injury, while an M2 phenotype down-regulated inflammatory cytokine and chemokine expression, reduced renal injury, and promoted resolution[81]. Interestingly, LXs have been shown to reprogram cytokine-primed M $\phi$ with a "classically activated" M1 phenotype to an "alternatively activated" M2 phenotype[40] and could therefore be therapeutically 
interesting in the context of reprogramming the phenotype of renal macrophages. As previously mentioned, LXs promote nonphlogistic phagocytosis, i.e., the phagocytic process does not provoke release of proinflammatory mediators of apoptotic cells, including PMN and lymphocytes[41]. LXs appear to promote this type of phagocytosis by modulating the actin cytoskeleton, through dephosphorylation of myosin II A and redistribution of Cdc42[32,82]. Defective clearance of apoptotic cells by $\mathrm{M} \phi$ has been implicated in the pathogenesis of chronic nonresolving inflammatory conditions, such as glomerulonephritis[83]. The effect of LXs on the clearance of apoptotic cells in kidney disease needs to be investigated further, but other in vivo models have demonstrated the importance of the agent. For instance, LXs promote $\mathrm{M} \phi$ phagocytosis of apoptotic neutrophils in an experimental model of peritonitis[40]. RvDs and PD1 also modulate macrophage recruitment and activity, inhibiting LPSinduced TNF- $\alpha$ production in bone marrow-derived $\mathrm{M} \phi$ in vitro and furthermore reducing $\mathrm{M} \phi$ infiltration in an in vivo model of $\mathrm{I} / \mathrm{R}[57]$.

\section{Dendritic Cells}

In the kidney, dendritic cells (DCs) can either be resident or reflect monocyte infiltration. However, their role in renal disease is not entirely understood. In response to I/R injury, DCs increase production of inflammatory cytokines, such as TNF- $\alpha$, IL-6, MCP-1, and RANTES[84]. In fact, DCs have been identified as the predominant source of TNF- $\alpha$ in the early phase of I/R injury[84]. As antigen-presenting cells, DCs are an important link between innate and adaptive immunity. After first encountering an antigen deemed as pathogenic, they mature and migrate to lymph nodes, where they activate the adaptive immune response. Macconi et al.[85] presented interesting data suggesting that during renal injury, tubular epithelial cells can phagocytose and degrade antigens from the tubular lumen and present them to DCs. These, in turn, mature and migrate to draining lymph nodes, activating CD8+ T cells, which return to the kidney exacerbating tubular epithelial cell injury[85]. Whether or not DCs are influenced by $\mathrm{LXA}_{4}$ is slightly controversial. There is research suggesting that the LX receptor FPR2/ALX is down-regulated as monocytes differentiate into DCs[86]. However, Machado et al.[48] show that LXA 4 induces FPRL1 expression in DCs and furthermore triggers SOCS-2 expression. It has also been shown that LXs control DC migration and inhibit excessive production of IL-12[86]. Also, RvE1 has been shown to modulate murine DC IL-12 production[87] and LXs have been shown to negatively regulate LPS-induced differentiation of murine monocytes into DCs in vitro[88]. However, how proresolving mediators, such as LXs, resolvins, and protectins, affect renal DCs remains to be established.

\section{CYTOKINE AND CHEMOKINE EXPRESSION}

In renal inflammation and disease, infiltrating $\mathrm{M} \phi$ and lymphocytes are the main source of proinflammatory and profibrotic cytokines[89]. However, resident cells, such as endothelial and mesangial cells, contribute to the production of cytokines and chemokines[90]. LXs are well known to regulate cytokine and chemokine production, and could therefore be important tools in regulating inflammatory mediators in the kidney. Kieran et al. showed in 2003 that ATLs inhibit the expression of many pathogenic cytokines, growth factors, adhesion molecules, and proteases up-regulated in response to renal I/R[91]. For instance, $\mathrm{LXA}_{4}$ inhibits TNF- $\alpha$-induced production of interleukins[92] and connective tissue growth factor (CTGF) induced MCP-1 and RANTES[47] in rat mesangial cells. In neutrophils, LXs inhibit TNF- $\alpha$-induced IL-1 $\beta$, IL-4, and MCP-1[93], as well as LPS-induced IL-8 secretion[94]. As for M $\phi$, LXs have been associated with increased TGF- $\beta$ production, whereas IL- 8 is inhibited[41].

$\mathrm{NF}-\mathrm{kB}$ is a transcription factor vital in the onset of inflammation, regulating the transcription of numerous proinflammatory cytokines, chemokines, and adhesion molecules[95]. However, NF-kB seems to have a dual role in renal pathology, being important both for the inflammatory phase, but also for the 
resolution. Lawrence et al. first reported that NF- $\mathrm{KB}$ appears to promote resolution of inflammation and, using an in vivo model of pleural inflammation, showed that whereas blocking NF- $\kappa \mathrm{B}$ in the onset of inflammation reduced the inflammatory response, blocking it in the resolving phase had adverse side effects[96]. Panzer et al. later showed more specifically that in renal inflammation, NF- $\kappa \mathrm{B}$ has a biphasic activation where the first peak regulates inflammation and the second peak promotes resolution[97]. The first peak is dependent primarily on NF- $\mathrm{KB}$ p65/p50 heterodimers, which induce transcription of proinflammatory mediators such as MCP-1 and RANTES. The second peak is regulated by NF- $\mathrm{KB}$ p50/p50 heterodimers and seem to down-regulate MCP-1/CCL1 and RANTES/CCL5, as well as TNF$\alpha$ [97]. In accordance with this, other work has shown that NF- $\kappa B$ p50 can induce expression of antiinflammatory IL-10 transcription[98], while repressing expression of proinflammatory mediators such as TNF- $\alpha$ [99]. Thus, this body of work suggests that even though it may be beneficial to inhibit NF- $\kappa \mathrm{B}$ in the beginning of an inflammatory process, it can be inappropriate to do so during the resolving phase[96]. $\mathrm{LXA}_{4}$ has been shown to inhibit NF-кB in various cell lines. Decker et al. showed that $\mathrm{LXA}_{4}$ inhibits IL$1 \beta$-induced degradation of I $\kappa \mathrm{Ba}$, which sequesters $\mathrm{NF}-\kappa \mathrm{B}$ in the cytosol and thus reduces NF- $\kappa \mathrm{B}$ activity[39], and has also been found to inhibit NF- $\kappa B$ activation in human synovial fibroblasts[101]. Furthermore, $\mathrm{LXA}_{4}$ analogues inhibit NF- $\mathrm{B}$ p65 activation in human PMN and monocytes[94], and native $\mathrm{LXA}_{4}$ does the same in murine $\mathrm{M} \phi[88]$. More specifically for the kidney, $\mathrm{LXA}_{4}$ has been shown to inhibit CTGF-induced NF- $\kappa \mathrm{B}$ activity in mesangial cells[47] and an $\mathrm{LXA}_{4}$ analogue that was protective in a model of nephritis in rats reduced NF- $\kappa B$ activation[65]. Hudert et al. have shown that $\omega-3$ PUFA reduces NF- $\kappa \mathrm{B}$ p50/p65 activity in a mouse model of colitis[102]. Furthermore, PD1 has been shown to inhibit NF- $\mathrm{kB}$ p50/p65 expression in a rat model of $\mathrm{I} / \mathrm{R}$ in the brain[58].

\section{Mesangial Cells}

It is well established that LXs can inhibit PDGF-, CTGF-, LTD $4^{-}$, and TNF- $\alpha$-induced proliferation and cell cycle progression in mesangial cells, both in vivo and in vitro[47,92,103,104,105]. Furthermore, Mitchell et al. showed that LXA 4 inhibits PDGF-induced ROS production in human mesangial cells[104], which express the FPR2/ALX[46]. Wu et al. demonstrate the protective effects of LXs in mesangioproliferative nephritis model in rats, where LXs inhibited IL-6 and IL- $1 \beta$ expression as well as reducing $\alpha$-smooth muscle actin ( $\alpha$-SMA) levels and NF- $\kappa B$ activation[106]. Mesangial cells control renal blood flow and thus also glomerular filtration rate (GFR) via their contractile properties. $\mathrm{LXA}_{4}$ increases renal plasma flow (RPF) and GFR in a dose-dependent manner[107]. Badr et al. also confirmed that $\mathrm{LXA}_{4}$ antagonizes $\mathrm{LTD}_{4}$-induced falls in GFR, however not in RPF[105]. One mechanism by which LXs restore pathological alterations of vascular tone is via inhibiting mesangial proliferation and contractility by antagonizing the cys LT receptor[105] and causing vasodilatation by inducing production of nitric oxide[42].

The heme-oxygenase-1 (HO-1) pathway has proven to be protective in several models of renal disease, both in rodents and humans[108]. The HO-1 enzyme system catalyzes the degradation of toxic heme into bile pigment, biliverdin, and carbon monoxide (CO), which have antioxidant and antiinflammatory properties and improve blood flow in rat renal transplantation models[109]. HO-1 also regulates gene expression as seen in $\mathrm{HO}^{--}$mice, which have increased MCP-1 and NF- $\mathrm{kB}$ expression and are more sensitive to I/R injury compared to wild-type animals[110]. LXs increase HO-1 expression in the eye[111] and in endothelial cells[112]. Furthermore, Hassan and Gronert hypothesize that part of the mechanism of action underlying the renoprotective actions of ATLs and PD1 is that they induce the HO-1 pathway, since its expression is increased both in vivo after I/R and in vitro in rat mesangial cells[66]. 


\section{Fibrosis}

Renal fibrosis, or tissue scarring, is the final outcome of CKD that does not resolve, regardless of etiology, and pathological features include glomerulosclerosis, tubulointerstitial fibrosis, inflammation, and loss of parenchyma. Fibrosis, in turn, causes end-stage renal failure, which requires dialysis and eventually transplantation. Glomerular mesangial cells, interstitial fibroblasts, and tubular epithelial cells are the major fibrogenic cell types, and infiltrating leukocytes also play an important role[113].

Renal fibrosis is a dynamic process with myofibroblastic activation of mesangial cells and fibroblasts being an early event, and epithelial to mesenchymal transition (EMT) occurring later[113]. Activated fibroblasts, so-called myofibroblasts, are particularly important in renal fibrosis. Recognized by their de novo production of $\alpha$-SMA, they produce excessive amounts of ECM and activate other renal cells to do the same. Renal myofibroblasts can be derived from residing fibroblasts, EMT, endothelial to mesenchymal transition (EndMT), bone marrow-derived cells, or from other mesenchymal cells[114]. Interestingly, $\mathrm{LXA}_{4}$ inhibits IL- $\beta$-induced production of inflammatory cytokines and matrix metalloproteinase (MMP)-3 production in human synovial fibroblasts[100]. Furthermore, recent data from our laboratory indicate that $\mathrm{LXA}_{4}$ can modulate renal fibroblast activation in response to various cytokines, including TGF- $\beta 1$, as evidenced by abrogated CTGF and $\alpha$-SMA production in TGF- $\beta 1-$ stimulated renal fibroblasts[115].

Renal fibrosis is characterized by excessive accumulation of ECM, derived from myofibroblasts, mesangial cells, and tubular epithelial cells that have undergone a phenotypic switch and become fibrotic[113]. ECM is primarily made up of components such as collagens, laminins, elastins, and tenacins that often cross-link and become resistant to degradation. It has been hypothesized that the extent of renal fibrosis is due to a balance between collagen synthesis and degradation, where a reduction in the latter results in fibrosis, although new data suggest that this might be slightly oversimplified[114,116]. Most renal ECM degradation is due to MMPs. Interestingly, $\mathrm{LXA}_{4}$ has been shown to prevent IL-1 $\beta$ induced MMP-3 in human synovial fibroblasts[100] and down-regulates MMP-2 and -9 in human hepatoma cells[117]. Furthermore, an ATL analogue reduced VEGF-induced MMP-9 activity in endothelial cells obtained from human umbilical cord[118].

In renal fibrosis, EMT begins as a part of the repair process after tissue injury and is associated with inflammation, ceasing when inflammation is resolved[119]. However, if the inflammation persists, EMT contributes to fibrosis. During EMT, the epithelial cells of the renal tubules are proposed to acquire a mesenchymal phenotype due to prolonged exposure of inflammatory and profibrotic signals[119]. This increases their migratory abilities and invasiveness, elevates their resistance to apoptosis, and increases production of ECM. The epithelial/mesenchymal cells, together with inflammatory cells and myofibroblasts, induce production of chemokines and MMPs, which cause basement membrane damage and focal degradation of type IV collagen and laminin[119,120]. When the underlying basement membrane is degraded in this manner, the cells can migrate into the interstitium, developing a fibroblastic phenotype and contributing to the pathogenesis of fibrosis, e.g., by producing ECM[121]. Rodgers et al. found that LXs in vitro can prevent PDGF-induced EMT in human mesangial cells[122]. Furthermore, LXs have been implicated to play a role in regulating EMT in human pulmonary epithelial cells[123]. Even though RvDs and PD1 seem to primarily affect leukocytes, it is possible that the compounds also effect residing renal cells, although they were unable to protect proximal tubular cells from a swine lineage from oxidative stress[57].

Although TGF- $\beta 1$ is considered an anti-inflammatory and proresolving cytokine, it is one of the major villains in renal fibrosis and a hallmark of practically all human and experimental forms of CKD[124]. TGF- $\beta 1$ causes fibrogenic cell activation, ECM accumulation, and EMT[125], and TGF- $\beta 1$ transgenic mice present with increased apoptosis of podocytes[126]. Furthermore, rats overexpressing TGF- $\beta 1$ develop glomerulosclerosis and interstitial fibrosis[127], and chronic inhibition of TGF- $\beta 1$ using TGF- $\beta 1-$ neutralizing antibody inhibits glomerulosclerosis and renal insufficiency in a model of type 2 diabetes[128]. Interestingly, Ma et al. showed, using a nephropathy model, that the effect of TGF- $\beta$ in the 
kidney is highly dose dependent as only lower doses of TGF- $\beta$-neutralizing antibody improved renal function, seemingly due to decreased glomerular infiltration of $M \phi[129]$. However, it should be mentioned that some research suggests that TGF- $\beta$ may have a much more complex role in the kidney then merely being profibrotic[77]. TGF- $\beta 1$ seems to deactivate $\mathrm{M} \phi$ to a phenotype that is proresolving, inducing collagen VI, which is a marker of an M2 phenotype[130]. TGF- $\beta 1$ also induces SMAD-7 signaling, which apart from working as a negative feedback loop on TGF- $\beta$ signaling, also inhibits NF$\kappa \mathrm{B}$, thereby reducing renal inflammation and proteinuria[131]. Furthermore, mice overexpressing latent TGF- $\beta 1$ were actually protective from renal fibrosis in a UUO model, mainly due its anti-inflammatory effects[132]. $\mathrm{LXA}_{4}$-associated phagocytosis is coupled to TGF- $\beta 1$ release, which is consistent with an immune modulatory phenotype[40]. However, LXs seems to have a different role in renal disease, as Rodgers et al. found that in PDGF-stimulated human mesangial cells, $\mathrm{LXA}_{4}$ reduces TGF- $\beta 1$ secretion and its downstream targets[122].

\section{CONCLUSION}

Inflammation is a central part of renal pathology and resolution of renal inflammation is vital for the return to normal kidney function following an injury. The resolution of renal inflammation is a complex process, where proresolving lipid mediators, such as LXs, resolvins and protectins, play an important role. LXs, resolvins and protectins actively contribute to the resolution of renal inflammation by inhibiting PMN and monocyte recruitment, shifting the cytokine milieu, and inhibiting mesangial proliferation and possibly EMT. Thus, these proresolving lipid mediators could have great potential as therapeutic targets in renal disease.

\section{ACKNOWLEDGMENTS}

Emma Börgeson is a recipient of an IRCSET Embark postgraduate research scholarship. Work in Professor Godson's laboratory is supported by Science Foundation Ireland, the Health Research Board, and the Government of Ireland Programme for Research in Third Level Institutions.

\section{REFERENCES}

1. Maderna, P. and Godson, C. (2009) Lipoxins: resolutionary road. Br. J. Pharmacol. 158, 947-959.

2. Serhan, C.N., Yacoubian, S., and Yang, R. (2008) Anti-inflammatory and proresolving lipid mediators. Annu. Rev. Pathol. 3, 279-312.

3. Serhan, C.N. (2009) Systems approach to inflammation resolution: identification of novel anti-inflammatory and proresolving mediators. J. Thromb. Haemost. 7(Suppl 1), 44-48.

4. Serhan, C.N. and Savill, J. (2005) Resolution of inflammation: the beginning programs the end. Nat. Immunol. 6, 1191-1197.

5. Levy, B.D., Clish, C.B., Schmidt, B., Gronert, K., and Serhan, C.N. (2001) Lipid mediator class switching during acute inflammation: signals in resolution. Nat. Immunol. 2, 612-619.

6. Ferenbach, D., Kluth, D.C., and Hughes, J. (2007) Inflammatory cells in renal injury and repair. Semin. Nephrol. 27, 250-259.

7. Wu, S.H., Liao, P.Y., Yin, P.L., Zhang, Y.M., and Dong, L. (2009) Elevated expressions of 15-lipoxygenase and lipoxin A4 in children with acute poststreptococcal glomerulonephritis. Am. J. Pathol. 174, 115-122.

8. Rivero, A., Mora, C., Muros, M., Garcia, J., Herrera, H., and Navarro-Gonzalez, J.F. (2009) Pathogenic perspectives for the role of inflammation in diabetic nephropathy. Clin. Sci. (Lond.) 116, 479-492.

9. Serhan, C.N., Hamberg, M., and Samuelsson, B. (1984) Lipoxins: novel series of biologically active compounds formed from arachidonic acid in human leukocytes. Proc. Natl. Acad. Sci. U. S. A. 81, 5335-5339.

10. Serhan, C.N., Wong, P.Y., and Samuelsson, B. (1987) Nomenclature of lipoxins and related compounds derived from arachidonic acid and eicosapentaenoic acid. Prostaglandins 34, 201-204.

11. Serhan, C.N. (2005) Lipoxins and aspirin-triggered 15-epi-lipoxins are the first lipid mediators of endogenous anti- 
inflammation and resolution. Prostaglandins Leukot. Essent. Fatty Acids 73, 141-162.

12. Parkinson, J.F. (2006) Lipoxin and synthetic lipoxin analogs: an overview of anti-inflammatory functions and new concepts in immunomodulation. Inflamm. Allergy Drug Targets 5, 91-106.

13. Serhan, C.N. (2007) Resolution phase of inflammation: novel endogenous anti-inflammatory and proresolving lipid mediators and pathways. Annu. Rev. Immunol. 25, 101-137.

14. Lefer, A.M., Stahl, G.L., Lefer, D.J., Brezinski, M.E., Nicolaou, K.C., Veale, C.A., Abe, Y., and Smith, J.B. (1988) Lipoxins A4 and B4: comparison of icosanoids having bronchoconstrictor and vasodilator actions but lacking platelet aggregatory activity. Proc. Natl. Acad. Sci. U. S. A. 85, 8340-8344.

15. Brezinski, M.E. and Serhan, C.N. (1990) Selective incorporation of (15S)-hydroxyeicosatetraenoic acid in phosphatidylinositol of human neutrophils: agonist-induced deacylation and transformation of stored hydroxyeicosanoids. Proc. Natl. Acad. Sci. U. S. A. 87, 6248-6252.

16. Claria, J. and Serhan, C.N. (1995) Aspirin triggers previously undescribed bioactive eicosanoids by human endothelial cell-leukocyte interactions. Proc. Natl. Acad. Sci. U. S. A. 92, 9475-9479.

17. Morris, T., Stables, M., and Gilroy, D.W. (2006) New perspectives on aspirin and the endogenous control of acute inflammatory resolution. TheScientificWorldJOURNAL 6, 1048-1065.

18. Serhan, C.N. and Chiang, N. (2002) Lipid-derived mediators in endogenous anti-inflammation and resolution: lipoxins and aspirin-triggered 15-epi-lipoxins. TheScientificWorldJOURNAL 2, 169-204.

19. Chiang, N., Bermudez, E.A., Ridker, P.M., Hurwitz, S., and Serhan, C.N. (2004) Aspirin triggers antiinflammatory 15-epi-lipoxin A4 and inhibits thromboxane in a randomized human trial. Proc. Natl. Acad. Sci. U. S. A. 101, 1517815183.

20. Birnbaum, Y., Ye, Y., Lin, Y., Freeberg, S.Y., Huang, M.H., Perez-Polo, J.R., and Uretsky, B.F. (2007) Aspirin augments 15-epi-lipoxin A4 production by lipopolysaccharide, but blocks the pioglitazone and atorvastatin induction of 15-epi-lipoxin A4 in the rat heart. Prostaglandins Other Lipid Mediat. 83, 89-98.

21. Serhan, C.N., Maddox, J.F., Petasis, N.A., Akritopoulou-Zanze, I., Papayianni, A., Brady, H.R., Colgan, S.P., and Madara, J.L. (1995) Design of lipoxin A4 stable analogs that block transmigration and adhesion of human neutrophils. Biochemistry 34, 14609-14615.

22. Maddox, J.F., Hachicha, M., Takano, T., Petasis, N.A., Fokin, V.V., and Serhan, C.N. (1997) Lipoxin A4 stable analogs are potent mimetics that stimulate human monocytes and THP-1 cells via a G-protein-linked lipoxin A4 receptor. J. Biol. Chem. 272, 6972-6978.

23. Fiorucci, S., Wallace, J.L., Mencarelli, A., Distrutti, E., Rizzo, G., Farneti, S., Morelli, A., Tseng, J.L., Suramanyam, B., Guilford, W.J., and Parkinson, J.F. (2004) A beta-oxidation-resistant lipoxin A4 analog treats hapten-induced colitis by attenuating inflammation and immune dysfunction. Proc. Natl. Acad. Sci. U. S. A. 101, 15736-15741.

24. Gewirtz, A.T., Collier-Hyams, L.S., Young, A.N., Kucharzik, T., Guilford, W.J., Parkinson, J.F., Williams, I.R., Neish, A.S., and Madara, J.L. (2002) Lipoxin a4 analogs attenuate induction of intestinal epithelial proinflammatory gene expression and reduce the severity of dextran sodium sulfate-induced colitis. J. Immunol. 168, 5260-5267.

25. Fiore, S., Ryeom, S.W., Weller, P.F., and Serhan, C.N. (1992) Lipoxin recognition sites. Specific binding of labeled lipoxin A4 with human neutrophils. J. Biol. Chem. 267, 16168-16176.

26. Chiang, N., Serhan, C.N., Dahlen, S.E., Drazen, J.M., Hay, D.W., Rovati, G.E., Shimizu, T., Yokomizo, T., and Brink, C. (2006) The lipoxin receptor ALX: potent ligand-specific and stereoselective actions in vivo. Pharmacol. Rev. 58, 463-487.

27. Fierro, I.M., Colgan, S.P., Bernasconi, G., Petasis, N.A., Clish, C.B., Arita, M., and Serhan, C.N. (2003) Lipoxin A4 and aspirin-triggered 15-epi-lipoxin A4 inhibit human neutrophil migration: comparisons between synthetic 15 epimers in chemotaxis and transmigration with microvessel endothelial cells and epithelial cells. J. Immunol. 170, 2688-2694.

28. Leonard, M.O., Hannan, K., Burne, M.J., Lappin, D.W., Doran, P., Coleman, P., Stenson, C., Taylor, C.T., Daniels, F., Godson, C., Petasis, N.A., Rabb, H., and Brady, H.R. (2002) 15-Epi-16-(para-fluorophenoxy)-lipoxin A(4)-methyl ester, a synthetic analogue of 15-epi-lipoxin $\mathrm{A}(4)$, is protective in experimental ischemic acute renal failure. $J$. Am. Soc. Nephrol. 13, 1657-1662.

29. Levy, B.D., Kohli, P., Gotlinger, K., Haworth, O., Hong, S., Kazani, S., Israel, E., Haley, K.J., and Serhan, C.N. (2007) Protectin D1 is generated in asthma and dampens airway inflammation and hyperresponsiveness. J. Immunol. 178, 496-502.

30. O'Sullivan, T.P., Vallin, K.S., Shah, S.T., Fakhry, J., Maderna, P., Scannell, M., Sampaio, A.L., Perretti, M., Godson, C., and Guiry, P.J. (2007) Aromatic lipoxin A4 and lipoxin B4 analogues display potent biological activities. J. Med. Chem. 50, 5894-5902.

31. Petasis, N.A., Keledjian, R., Sun, Y.P., Nagulapalli, K.C., Tjonahen, E., Yang, R., and Serhan, C.N. (2008) Design and synthesis of benzo-lipoxin A4 analogs with enhanced stability and potent anti-inflammatory properties. Bioorg. Med. Chem. Lett. 18, 1382-1387.

32. Reville, K., Crean, J.K., Vivers, S., Dransfield, I., and Godson, C. (2006) Lipoxin A4 redistributes myosin IIA and Cdc42 in macrophages: implications for phagocytosis of apoptotic leukocytes. J. Immunol. 176, 1878-1888.

33. Serhan, C.N. (2004) Clues for new therapeutics in osteoporosis and periodontal disease: new roles for lipoxygenases? Expert Opin. Ther. Targets 8, 643-652.

34. Kantarci, A., Hasturk, H., and Van Dyke, T.E. (2006) Host-mediated resolution of inflammation in periodontal 
diseases. Periodontol 2000 40, 144-163.

35. Kantarci, A. and Van Dyke, T.E. (2005) Lipoxin signaling in neutrophils and their role in periodontal disease. Prostaglandins Leukot. Essent. Fatty Acids 73, 289-299.

36. Lee, T.H., Horton, C.E., Kyan-Aung, U., Haskard, D., Crea, A.E., and Spur, B.W. (1989) Lipoxin A4 and lipoxin B4 inhibit chemotactic responses of human neutrophils stimulated by leukotriene B4 and N-formyl-L-methionyl-Lleucyl-L-phenylalanine. Clin. Sci. (Lond.) 77, 195-203.

37. Bandeira-Melo, C., Bozza, P.T., Diaz, B.L., Cordeiro, R.S., Jose, P.J., Martins, M.A., and Serhan, C.N. (2000) Cutting edge: lipoxin (LX) A4 and aspirin-triggered 15-epi-LXA4 block allergen-induced eosinophil trafficking. $J$. Immunol. 164, 2267-2271.

38. Qiu, F.H., Devchand, P.R., Wada, K., and Serhan, C.N. (2001) Aspirin-triggered lipoxin A4 and lipoxin A4 upregulate transcriptional corepressor NAB1 in human neutrophils. FASEB J. 15, 2736-2738.

39. Decker, Y., McBean, G., and Godson, C. (2009) Lipoxin A4 inhibits IL-1beta-induced IL-8 and ICAM-1 expression in 1321N1 human astrocytoma cells. Am. J. Physiol. Cell Physiol. 296, C1420-1427.

40. Mitchell, S., Thomas, G., Harvey, K., Cottell, D., Reville, K., Berlasconi, G., Petasis, N.A., Erwig, L., Rees, A.J., Savill, J., Brady, H.R., and Godson, C. (2002) Lipoxins, aspirin-triggered epi-lipoxins, lipoxin stable analogues, and the resolution of inflammation: stimulation of macrophage phagocytosis of apoptotic neutrophils in vivo. J. Am. Soc. Nephrol. 13, 2497-2507.

41. Godson, C., Mitchell, S., Harvey, K., Petasis, N.A., Hogg, N., and Brady, H.R. (2000) Cutting edge: lipoxins rapidly stimulate nonphlogistic phagocytosis of apoptotic neutrophils by monocyte-derived macrophages. J. Immunol. 164, $1663-1667$.

42. von der Weid, P.Y., Hollenberg, M.D., Fiorucci, S., and Wallace, J.L. (2004) Aspirin-triggered, cyclooxygenase-2dependent lipoxin synthesis modulates vascular tone. Circulation 110, 1320-1325.

43. Fiore, S., Maddox, J.F., Perez, H.D., and Serhan, C.N. (1994) Identification of a human cDNA encoding a functional high affinity lipoxin A4 receptor. J. Exp. Med. 180, 253-260.

44. Ye, R.D., Boulay, F., Wang, J.M., Dahlgren, C., Gerard, C., Parmentier, M., Serhan, C.N., and Murphy, P.M. (2009) International Union of Basic and Clinical Pharmacology. LXXIII. Nomenclature for the formyl peptide receptor (FPR) family. Pharmacol. Rev. 61, 119-161.

45. Krishnamoorthy, S., Recchiuti, A., Chiang, N., Yacoubian, S., Lee, C.H., Yang, R., Petasis, N.A., and Serhan, C.N. (2010) Resolvin D1 binds human phagocytes with evidence for proresolving receptors. Proc. Natl. Acad. Sci. U. S. A. 107, 1660-1665.

46. McMahon, B., Stenson, C., McPhillips, F., Fanning, A., Brady, H.R., and Godson, C. (2000) Lipoxin A4 antagonizes the mitogenic effects of leukotriene D4 in human renal mesangial cells. Differential activation of MAP kinases through distinct receptors. J. Biol. Chem. 275, 27566-27575.

47. Wu, S.H., Wu, X.H., Lu, C., Dong, L., Zhou, G.P., and Chen, Z.Q. (2006) Lipoxin A4 inhibits connective tissue growth factor-induced production of chemokines in rat mesangial cells. Kidney Int. 69, 248-256.

48. Machado, F.S., Johndrow, J.E., Esper, L., Dias, A., Bafica, A., Serhan, C.N., and Aliberti, J. (2006) Antiinflammatory actions of lipoxin A4 and aspirin-triggered lipoxin are SOCS-2 dependent. Nat. Med. 12, 330-334.

49. Machado, F.S. and Aliberti, J. (2008) Role of lipoxin in the modulation of immune response during infection. Int. Immunopharmacol. 8, 1316-1319.

50. Tobin, D.M., Vary, J.C., Jr., Ray, J.P., Walsh, G.S., Dunstan, S.J., Bang, N.D., Hagge, D.A., Khadge, S., King, M.C., Hawn, T.R., Moens, C.B., and Ramakrishnan, L. (2010) The lta4h locus modulates susceptibility to mycobacterial infection in zebrafish and humans. Cell 140, 717-730.

51. Herb, F., Thye, T., Niemann, S., Browne, E.N., Chinbuah, M.A., Gyapong, J., Osei, I., Owusu-Dabo, E., Werz, O., Rusch-Gerdes, S., Horstmann, R.D., and Meyer, C.G. (2008) ALOX5 variants associated with susceptibility to human pulmonary tuberculosis. Hum. Mol. Genet. 17, 1052-1060.

52. Serhan, C.N., Hong, S., Gronert, K., Colgan, S.P., Devchand, P.R., Mirick, G., and Moussignac, R.L. (2002) Resolvins: a family of bioactive products of omega-3 fatty acid transformation circuits initiated by aspirin treatment that counter proinflammation signals. J. Exp. Med. 196, 1025-1037.

53. Schwab, J.M., Chiang, N., Arita, M., and Serhan, C.N. (2007) Resolvin E1 and protectin D1 activate inflammationresolution programmes. Nature 447, 869-874.

54. Hasturk, H., Kantarci, A., Ohira, T., Arita, M., Ebrahimi, N., Chiang, N., Petasis, N.A., Levy, B.D., Serhan, C.N., and Van Dyke, T.E. (2006) RvE1 protects from local inflammation and osteoclast-mediated bone destruction in periodontitis. FASEB J. 20, 401-403.

55. Arita, M., Yoshida, M., Hong, S., Tjonahen, E., Glickman, J.N., Petasis, N.A., Blumberg, R.S., and Serhan, C.N. (2005) Resolvin E1, an endogenous lipid mediator derived from omega-3 eicosapentaenoic acid, protects against 2,4,6-trinitrobenzene sulfonic acid-induced colitis. Proc. Natl. Acad. Sci. U. S. A. 102, 7671-7676.

56. Connor, K.M., SanGiovanni, J.P., Lofqvist, C., Aderman, C.M., Chen, J., Higuchi, A., Hong, S., Pravda, E.A., Majchrzak, S., Carper, D., Hellstrom, A., Kang, J.X., Chew, E.Y., Salem, N., Jr., Serhan, C.N., and Smith, L.E. (2007) Increased dietary intake of omega-3-polyunsaturated fatty acids reduces pathological retinal angiogenesis. Nat. Med. 13, 868-873.

57. Duffield, J.S., Hong, S., Vaidya, V.S., Lu, Y., Fredman, G., Serhan, C.N., and Bonventre, J.V. (2006) Resolvin D series and protectin D1 mitigate acute kidney injury. J. Immunol. 177, 5902-5911. 
58. Marcheselli, V.L., Hong, S., Lukiw, W.J., Tian, X.H., Gronert, K., Musto, A., Hardy, M., Gimenez, J.M., Chiang, N., Serhan, C.N., and Bazan, N.G. (2003) Novel docosanoids inhibit brain ischemia-reperfusion-mediated leukocyte infiltration and pro-inflammatory gene expression. J. Biol. Chem. 278, 43807-43817.

59. Lukiw, W.J., Cui, J.G., Marcheselli, V.L., Bodker, M., Botkjaer, A., Gotlinger, K., Serhan, C.N., and Bazan, N.G. (2005) A role for docosahexaenoic acid-derived neuroprotectin D1 in neural cell survival and Alzheimer disease. $J$. Clin. Invest. 115, 2774-2783.

60. Kohli, P. and Levy, B.D. (2009) Resolvins and protectins: mediating solutions to inflammation. Br. J. Pharmacol. 158, 960-971.

61. Schieppati, A. and Remuzzi, G. (2005) Chronic renal diseases as a public health problem: epidemiology, social, and economic implications. Kidney Int. Suppl. S7-S10.

62. Ritz, E., Rychlik, I., Locatelli, F., and Halimi, S. (1999) End-stage renal failure in type 2 diabetes: a medical catastrophe of worldwide dimensions. Am. J. Kidney Dis. 34, 795-808.

63. Liu, Y. (2004) Epithelial to mesenchymal transition in renal fibrogenesis: pathologic significance, molecular mechanism, and therapeutic intervention. J. Am. Soc. Nephrol. 15, 1-12.

64. Kieran, N.E., Maderna, P., and Godson, C. (2004) Lipoxins: potential anti-inflammatory, proresolution, and antifibrotic mediators in renal disease. Kidney Int. 65, 1145-1154.

65. Wu, S.H., Liao, P.Y., Dong, L., and Jiang, X.Y. (2006) [Protective effects of 15-methyl-lipoxin A4 on mesangioproliferative nephritis in rats]. Zhongguo Dang Dai Er Ke Za Zhi 8, 225-230.

66. Hassan, I.R. and Gronert, K. (2009) Acute changes in dietary omega-3 and omega-6 polyunsaturated fatty acids have a pronounced impact on survival following ischemic renal injury and formation of renoprotective docosahexaenoic acid-derived protectin D1. J. Immunol. 182, 3223-3232.

67. Neumayer, H.H., Heinrich, M., Schmissas, M., Haller, H., Wagner, K., and Luft, F.C. (1992) Amelioration of ischemic acute renal failure by dietary fish oil administration in conscious dogs. J. Am. Soc. Nephrol. 3, 1312-1320.

68. Dillon, J.J. (1997) Fish oil therapy for IgA nephropathy: efficacy and interstudy variability. J. Am. Soc. Nephrol. 8, 1739-1744.

69. Donadio, J.V. and Grande, J.P. (2002) IgA nephropathy. N. Engl. J. Med. 347, 738-748.

70. Kielar, M.L., Jeyarajah, D.R., Zhou, X.J., and Lu, C.Y. (2003) Docosahexaenoic acid ameliorates murine ischemic acute renal failure and prevents increases in mRNA abundance for both TNF-alpha and inducible nitric oxide synthase. J. Am. Soc. Nephrol. 14, 389-396.

71. Jia, Q., Shi, Y., Bennink, M.B., and Pestka, J.J. (2004) Docosahexaenoic acid and eicosapentaenoic acid, but not alphalinolenic acid, suppress deoxynivalenol-induced experimental IgA nephropathy in mice. J. Nutr. 134, 1353-1361.

72. An, W.S., Kim, H.J., Cho, K.H., and Vaziri, N.D. (2009) Omega-3 fatty acid supplementation attenuates oxidative stress, inflammation, and tubulointerstitial fibrosis in the remnant kidney. Am. J. Physiol. 297, F895-903.

73. McMahon, B., Mitchell, S., Brady, H.R., and Godson, C. (2001) Lipoxins: revelations on resolution. Trends Pharmacol. Sci. 22, 391-395.

74. Mayadas, T.N., Mendrick, D.L., Brady, H.R., Tang, T., Papayianni, A., Assmann, K.J., Wagner, D.D., Hynes, R.O., and Cotran, R.S. (1996) Acute passive anti-glomerular basement membrane nephritis in P-selectin-deficient mice. Kidney Int. 49, 1342-1349.

75. Papayianni, A., Serhan, C.N., Phillips, M.L., Rennke, H.G., and Brady, H.R. (1995) Transcellular biosynthesis of lipoxin A4 during adhesion of platelets and neutrophils in experimental immune complex glomerulonephritis. Kidney Int. 47, 1295-1302.

76. Munger, K.A., Montero, A., Fukunaga, M., Uda, S., Yura, T., Imai, E., Kaneda, Y., Valdivielso, J.M., and Badr, K.F. (1999) Transfection of rat kidney with human 15-lipoxygenase suppresses inflammation and preserves function in experimental glomerulonephritis. Proc. Natl. Acad. Sci. U. S. A. 96, 13375-13380.

77. Ricardo, S.D., van Goor, H., and Eddy, A.A. (2008) Macrophage diversity in renal injury and repair. J. Clin. Invest. 118, 3522-3530.

78. Martinez, F.O., Sica, A., Mantovani, A., and Locati, M. (2008) Macrophage activation and polarization. Front. Biosci. 13, 453-461.

79. Mosser, D.M. and Edwards, J.P. (2008) Exploring the full spectrum of macrophage activation. Nat. Rev. 8, $958-969$.

80. Duffield, J.S. (2003) The inflammatory macrophage: a story of Jekyll and Hyde. Clin. Sci. (Lond.) 104, $27-38$.

81. Wang, Y., Wang, Y.P., Zheng, G., Lee, V.W., Ouyang, L., Chang, D.H., Mahajan, D., Coombs, J., Wang, Y.M., Alexander, S.I., and Harris, D.C. (2007) Ex vivo programmed macrophages ameliorate experimental chronic inflammatory renal disease. Kidney Int. 72, 290-299.

82. Maderna, P., Cottell, D.C., Berlasconi, G., Petasis, N.A., Brady, H.R., and Godson, C. (2002) Lipoxins induce actin reorganization in monocytes and macrophages but not in neutrophils: differential involvement of rho GTPases. Am. J. Pathol. 160, 2275-2283.

83. Mitchell, D.A., Taylor, P.R., Cook, H.T., Moss, J., Bygrave, A.E., Walport, M.J., and Botto, M. (1999) Cutting edge: C1q protects against the development of glomerulonephritis independently of C3 activation. J. Immunol. 162, 56765679.

84. Dong, X., Swaminathan, S., Bachman, L.A., Croatt, A.J., Nath, K.A., and Griffin, M.D. (2007) Resident dendritic cells are the predominant TNF-secreting cell in early renal ischemia-reperfusion injury. Kidney Int. 71, 619-628.

85. Macconi, D., Chiabrando, C., Schiarea, S., Aiello, S., Cassis, L., Gagliardini, E., Noris, M., Buelli, S., Zoja, C., 
Corna, D., Mele, C., Fanelli, R., Remuzzi, G., and Benigni, A. (2009) Proteasomal processing of albumin by renal dendritic cells generates antigenic peptides. J. Am. Soc. Nephrol. 20, 123-130.

86. Yang, D., Chen, Q., Le, Y., Wang, J.M., and Oppenheim, J.J. (2001) Differential regulation of formyl peptide receptor-like 1 expression during the differentiation of monocytes to dendritic cells and macrophages. J. Immunol. 166, 4092-4098.

87. Arita, M., Bianchini, F., Aliberti, J., Sher, A., Chiang, N., Hong, S., Yang, R., Petasis, N.A., and Serhan, C.N. (2005) Stereochemical assignment, antiinflammatory properties, and receptor for the omega-3 lipid mediator resolvin E1. $J$. Exp. Med. 201, 713-722.

88. Zhang, L., Wu, P., Jin, S.W., Yuan, P., Wan, J.Y., Zhou, X.Y., Xiong, W., Fang, F., and Ye, D.Y. (2007) Lipoxin A4 negatively regulates lipopolysaccharide-induced differentiation of RAW264.7 murine macrophages into dendritic-like cells. Chin. Med. J. 120, 981-987.

89. Anders, H.J., Vielhauer, V., and Schlondorff, D. (2003) Chemokines and chemokine receptors are involved in the resolution or progression of renal disease. Kidney Int. 63, 401-415.

90. Furuichi, K., Kaneko, S., and Wada, T. (2009) Chemokine/chemokine receptor-mediated inflammation regulates pathologic changes from acute kidney injury to chronic kidney disease. Clin. Exp. Nephrol. 13, 9-14.

91. Kieran, N.E., Doran, P.P., Connolly, S.B., Greenan, M.C., Higgins, D.F., Leonard, M., Godson, C., Taylor, C.T., Henger, A., Kretzler, M., Burne, M.J., Rabb, H., and Brady, H.R. (2003) Modification of the transcriptomic response to renal ischemia/reperfusion injury by lipoxin analog. Kidney Int. 64, 480-492.

92. Wu, S.H., Lu, C., Dong, L., Zhou, G.P., He, Z.G., and Chen, Z.Q. (2005) Lipoxin A4 inhibits TNF-alpha-induced production of interleukins and proliferation of rat mesangial cells. Kidney Int. 68, 35-46.

93. Hachicha, M., Pouliot, M., Petasis, N.A., and Serhan, C.N. (1999) Lipoxin (LX)A4 and aspirin-triggered 15-epiLXA4 inhibit tumor necrosis factor 1alpha-initiated neutrophil responses and trafficking: regulators of a cytokinechemokine axis. J. Exp. Med. 189, 1923-1930.

94. Jozsef, L., Zouki, C., Petasis, N.A., Serhan, C.N., and Filep, J.G. (2002) Lipoxin A4 and aspirin-triggered 15-epilipoxin A4 inhibit peroxynitrite formation, NF-kappa B and AP-1 activation, and IL-8 gene expression in human leukocytes. Proc. Natl. Acad. Sci. U. S. A. 99, 13266-13271.

95. Beinke, S. and Ley, S.C. (2004) Functions of NF-kappaB1 and NF-kappaB2 in immune cell biology. Biochem. J. 382, 393-409.

96. Lawrence, T., Gilroy, D.W., Colville-Nash, P.R., and Willoughby, D.A. (2001) Possible new role for NF-kappaB in the resolution of inflammation. Nat. Med. 7, 1291-1297.

97. Panzer, U., Steinmetz, O.M., Turner, J.E., Meyer-Schwesinger, C., von Ruffer, C., Meyer, T.N., Zahner, G., GomezGuerrero, C., Schmid, R.M., Helmchen, U., Moeckel, G.W., Wolf, G., Stahl, R.A., and Thaiss, F. (2009) Resolution of renal inflammation: a new role for NF-kappaB1 (p50) in inflammatory kidney diseases. Am. J. Physiol. 297, F429-439.

98. Cao, S., Zhang, X., Edwards, J.P., and Mosser, D.M. (2006) NF-kappaB1 (p50) homodimers differentially regulate pro- and anti-inflammatory cytokines in macrophages. J. Biol. Chem. 281, 26041-26050.

99. Baer, M., Dillner, A., Schwartz, R.C., Sedon, C., Nedospasov, S., and Johnson, P.F. (1998) Tumor necrosis factor alpha transcription in macrophages is attenuated by an autocrine factor that preferentially induces NF-kappaB p50. Mol. Cell. Biol. 18, 5678-5689.

100. Sodin-Semrl, S., Taddeo, B., Tseng, D., Varga, J., and Fiore, S. (2000) Lipoxin A4 inhibits IL-1 beta-induced IL-6, IL-8, and matrix metalloproteinase-3 production in human synovial fibroblasts and enhances synthesis of tissue inhibitors of metalloproteinases. J. Immunol. 164, 2660-2666.

101. Sodin-Semrl, S., Spagnolo, A., Mikus, R., Barbaro, B., Varga, J., and Fiore, S. (2004) Opposing regulation of interleukin-8 and NF-kappaB responses by lipoxin A4 and serum amyloid A via the common lipoxin A receptor. Int. J. Immunopathol. Pharmacol. 17, 145-156.

102. Hudert, C.A., Weylandt, K.H., Lu, Y., Wang, J., Hong, S., Dignass, A., Serhan, C.N., and Kang, J.X. (2006) Transgenic mice rich in endogenous omega-3 fatty acids are protected from colitis. Proc. Natl. Acad. Sci. U. S. A. 103, 11276-11281.

103. Mitchell, D., Rodgers, K., Hanly, J., McMahon, B., Brady, H.R., Martin, F., and Godson, C. (2004) Lipoxins inhibit Akt/PKB activation and cell cycle progression in human mesangial cells. Am. J. Pathol. 164, 937-946.

104. Mitchell, D., O'Meara, S.J., Gaffney, A., Crean, J.K., Kinsella, B.T., and Godson, C. (2007) The lipoxin A4 receptor is coupled to SHP-2 activation: implications for regulation of receptor tyrosine kinases. J. Biol. Chem. 282, 1560615618.

105. Badr, K.F., DeBoer, D.K., Schwartzberg, M., and Serhan, C.N. (1989) Lipoxin A4 antagonizes cellular and in vivo actions of leukotriene D4 in rat glomerular mesangial cells: evidence for competition at a common receptor. Proc. Natl. Acad. Sci. U. S. A. 86, 3438-3442.

106. Wu, S.H., Wu, X.H., Liao, P.Y., and Dong, L. (2007) Signal transduction involved in protective effects of 15(R/S)methyl- lipoxin A(4) on mesangioproliferative nephritis in rats. Prostaglandins Leukot. Essent. Fatty Acids 76, 173180 .

107. Katoh, T., Takahashi, K., DeBoer, D.K., Serhan, C.N., and Badr, K.F. (1992) Renal hemodynamic actions of lipoxins in rats: a comparative physiological study. Am. J. Physiol. 263, F436-442.

108. Jarmi, T. and Agarwal, A. (2009) Heme oxygenase and renal disease. Curr. Hypertens. Rep. 11, 56-62.

109. Nakao, A., Neto, J.S., Kanno, S., Stolz, D.B., Kimizuka, K., Liu, F., Bach, F.H., Billiar, T.R., Choi, A.M., Otterbein, 
L.E., and Murase, N. (2005) Protection against ischemia/reperfusion injury in cardiac and renal transplantation with carbon monoxide, biliverdin and both. Am. J. Transplant. 5, 282-291.

110. Pittock, S.T., Norby, S.M., Grande, J.P., Croatt, A.J., Bren, G.D., Badley, A.D., Caplice, N.M., Griffin, M.D., and Nath, K.A. (2005) MCP-1 is up-regulated in unstressed and stressed HO-1 knockout mice: pathophysiologic correlates. Kidney Int. 68, 611-622.

111. Biteman, B., Hassan, I.R., Walker, E., Leedom, A.J., Dunn, M., Seta, F., Laniado-Schwartzman, M., and Gronert, K. (2007) Interdependence of lipoxin A4 and heme-oxygenase in counter-regulating inflammation during corneal wound healing. FASEB J. 21, 2257-2266.

112. Nascimento-Silva, V., Arruda, M.A., Barja-Fidalgo, C., Villela, C.G., and Fierro, I.M. (2005) Novel lipid mediator aspirin-triggered lipoxin A4 induces heme oxygenase-1 in endothelial cells. Am. J. Physiol. Cell Physiol. 289, C557-563.

113. Liu, Y. (2006) Renal fibrosis: new insights into the pathogenesis and therapeutics. Kidney Int. 69, $213-217$.

114. Hewitson, T.D. (2009) Renal tubulointerstitial fibrosis: common but never simple. Am. J. Physiol. 296, F1239-1244.

115. Ryan, A., Murphy, M., Borgeson, E., Baker, N., Docherty, N., Godson, C. (2008) Novel fibro-suppressant activities of lipoxin A4 in renal cells. J. Am. Soc. Nephrol. 19, Abstr. TH-PO422.

116. Ronco, P., Lelongt, B., Piedagnel, R., and Chatziantoniou, C. (2007) Matrix metalloproteinases in kidney disease progression and repair: a case of flipping the coin. Semin. Nephrol. 27, 352-362.

117. Zhou, X.Y., Li, Y.S., Wu, P., Wang, H.M., Cai, Z.Y., Xu, F.Y., and Ye, D.Y. (2009) Lipoxin A(4) inhibited hepatocyte growth factor-induced invasion of human hepatoma cells. Hepatol. Res. 39, 921-930.

118. Cezar-de-Mello, P.F., Vieira, A.M., Nascimento-Silva, V., Villela, C.G., Barja-Fidalgo, C., and Fierro, I.M. (2008) ATL-1, an analogue of aspirin-triggered lipoxin A4, is a potent inhibitor of several steps in angiogenesis induced by vascular endothelial growth factor. Br. J. Pharmacol. 153, 956-965.

119. Kalluri, R. and Weinberg, R.A. (2009) The basics of epithelial-mesenchymal transition. J. Clin. Invest. 119, $1420-1428$.

120. Cheng, S., Pollock, A.S., Mahimkar, R., Olson, J.L., and Lovett, D.H. (2006) Matrix metalloproteinase 2 and basement membrane integrity: a unifying mechanism for progressive renal injury. FASEB J. 20, 1898-1900.

121. Potenta, S., Zeisberg, E., and Kalluri, R. (2008) The role of endothelial-to-mesenchymal transition in cancer progression. Br. J. Cancer 99, 1375-1379.

122. Rodgers, K., McMahon, B., Mitchell, D., Sadlier, D., and Godson, C. (2005) Lipoxin A4 modifies platelet-derived growth factor-induced pro-fibrotic gene expression in human renal mesangial cells. Am. J. Pathol. 167, 683-694.

123. Tai, H.H., Tong, M., and Ding, Y. (2007) 15-Hydroxyprostaglandin dehydrogenase (15-PGDH) and lung cancer. Prostaglandins Other Lipid Mediat. 83, 203-208.

124. Bottinger, E.P. (2007) TGF-beta in renal injury and disease. Semin. Nephrol. 27, 309-320.

125. Phillips, A. (2007) The role of proximal tubular cells in interstitial fibrosis: understanding TGF-beta1. Chang Gung Med. J. 30, 2-6.

126. Schiffer, M., Bitzer, M., Roberts, I.S., Kopp, J.B., ten Dijke, P., Mundel, P., and Bottinger, E.P. (2001) Apoptosis in podocytes induced by TGF-beta and Smad7. J. Clin. Invest. 108, 807-816.

127. Isaka, Y., Fujiwara, Y., Ueda, N., Kaneda, Y., Kamada, T., and Imai, E. (1993) Glomerulosclerosis induced by in vivo transfection of transforming growth factor-beta or platelet-derived growth factor gene into the rat kidney. J. Clin. Invest. 92, 2597-2601.

128. Ziyadeh, F.N., Hoffman, B.B., Han, D.C., Iglesias-De La Cruz, M.C., Hong, S.W., Isono, M., Chen, S., McGowan, T.A., and Sharma, K. (2000) Long-term prevention of renal insufficiency, excess matrix gene expression, and glomerular mesangial matrix expansion by treatment with monoclonal antitransforming growth factor-beta antibody in db/db diabetic mice. Proc. Natl. Acad. Sci. U. S. A. 97, 8015-8020.

129. Ma, L.J., Jha, S., Ling, H., Pozzi, A., Ledbetter, S., and Fogo, A.B. (2004) Divergent effects of low versus high dose anti-TGF-beta antibody in puromycin aminonucleoside nephropathy in rats. Kidney Int. 65, 106-115.

130. Schnoor, M., Cullen, P., Lorkowski, J., Stolle, K., Robenek, H., Troyer, D., Rauterberg, J., and Lorkowski, S. (2008) Production of type VI collagen by human macrophages: a new dimension in macrophage functional heterogeneity. $J$. Immunol. 180, 5707-5719.

131. Ng, Y.Y., Hou, C.C., Wang, W., Huang, X.R., and Lan, H.Y. (2005) Blockade of NFkappaB activation and renal inflammation by ultrasound-mediated gene transfer of Smad7 in rat remnant kidney. Kidney Int. Suppl. S83-91.

132. Wang, W., Huang, X.R., Li, A.G., Liu, F., Li, J.H., Truong, L.D., Wang, X.J., and Lan, H.Y. (2005) Signaling mechanism of TGF-beta1 in prevention of renal inflammation: role of Smad7. J. Am. Soc. Nephrol. 16, 1371-1383.

133. Poussu, A. (2001) Cloning and Characterization of Vear, a Novel Golgi-Associated Protein Involved in Vesicle Trafficking [Dissertation]. Oulu University, Finland.

\section{This article should be cited as follows:}

Börgeson, E. and Godson, C. (2010) Molecular circuits of resolution in renal disease. TheScientificWorldJOURNAL 10, 13701385. DOI 10.1100/tsw.2010.120. 


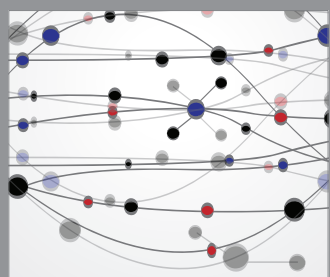

The Scientific World Journal
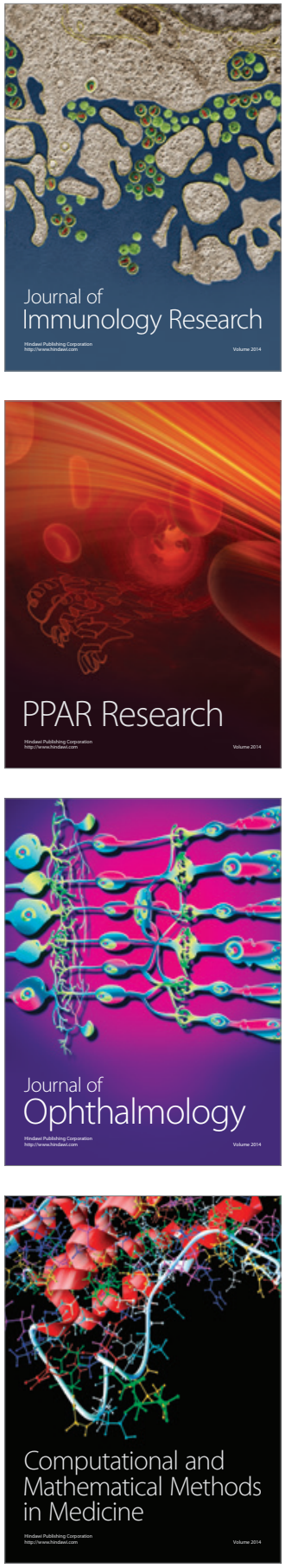

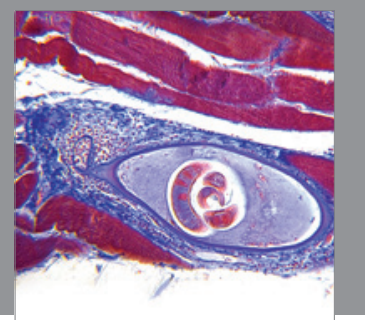

Gastroenterology

Research and Practice
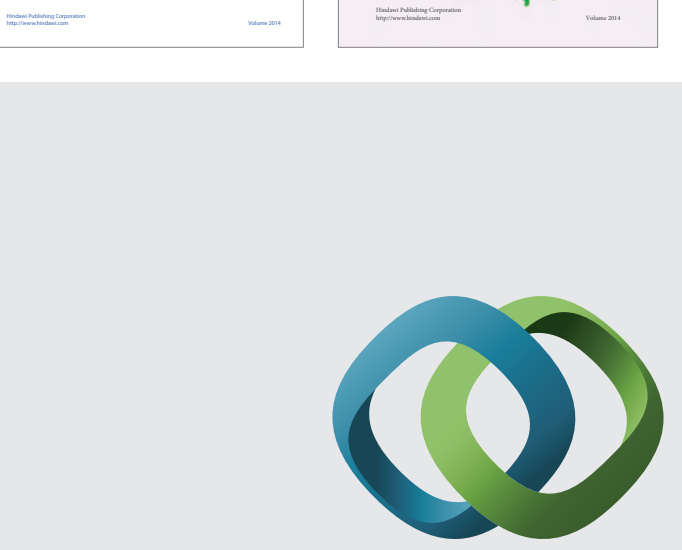

\section{Hindawi}

Submit your manuscripts at

http://www.hindawi.com
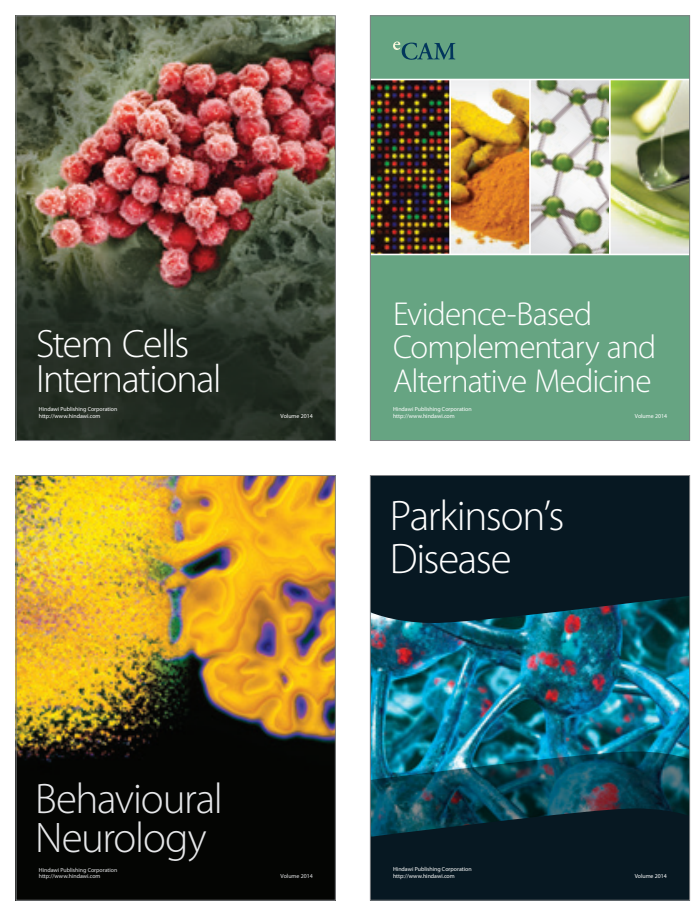

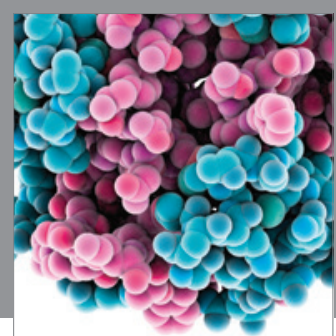

Journal of
Diabetes Research

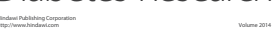

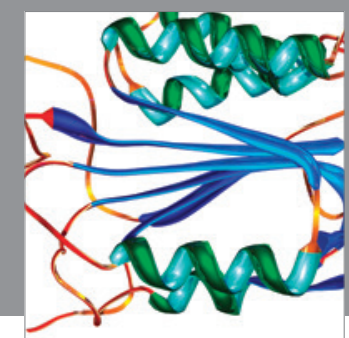

Disease Markers
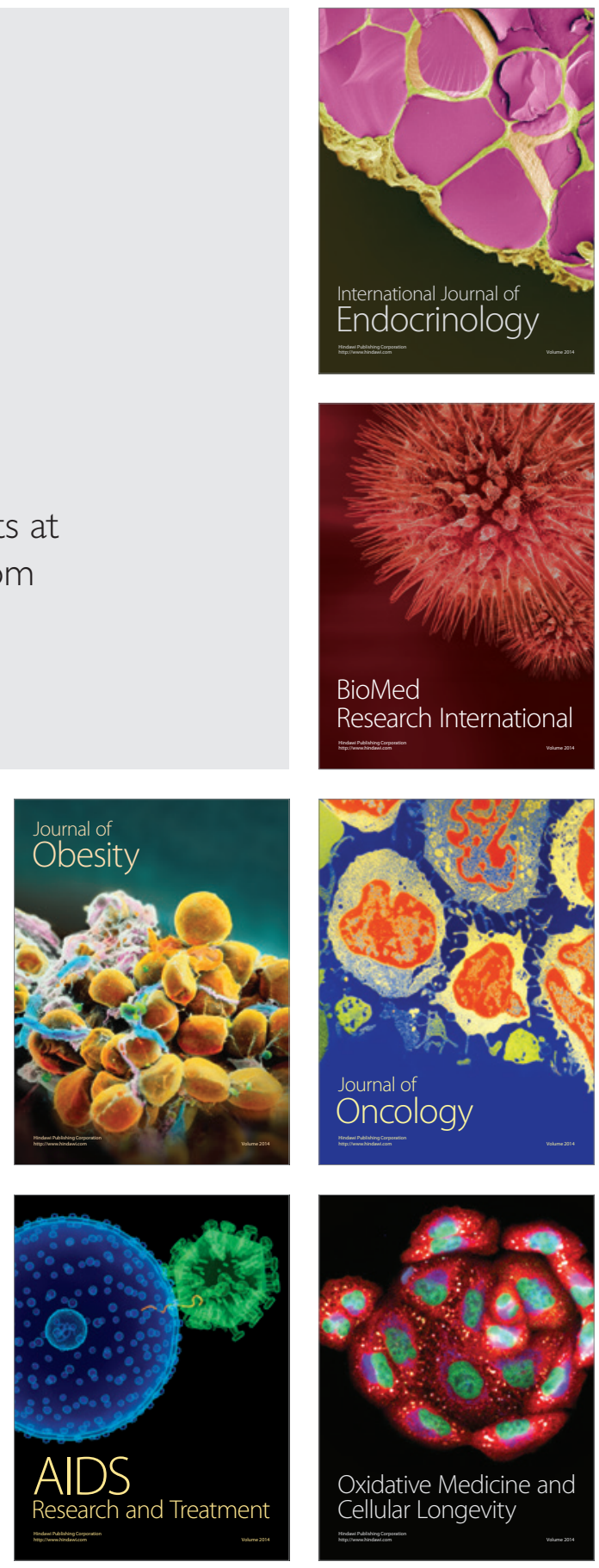